\title{
O PROGRAMA NAS/CNPq: AVALIAÇÃO DE UM PARTICIPANTE
}

\author{
Timothy John Brocksom*
}

Departamento de Química, Universidade Federal de São Carlos, CP 676, 13560-970 São Carlos - SP, Brasil

\begin{abstract}
THE NAS/CNPq PROGRAMME; PARTICIPANT'S OPINION. The NAS/CNPq programme in Chemistry ran from 1969 to 1974 , and brought recent $\mathrm{PhD}$ and post-doctoral chemists to the Chemistry Institutes at the University of São Paulo and the Federal University of Rio de Janeiro. The purpose was to create and direct new research topics in selected areas of chemistry, and participate in the postgraduate programmes. As a participant in this programme, I present my personal views, some background information, and an evaluation of this programme for the advance of synthetic organic chemistry in Brazil.
\end{abstract}

Keywords: NAS/CNPq programme; IQ-USP; synthetic organic chemistry.

\section{INTRODUÇÃO}

No final da década de 60 , enquanto eu fazia um estágio de pósdoutorado no laboratório do Prof. William (Bill) S. Johnson no Departamento de Química da Universidade de Stanford, ouvi os primeiros comentários sobre um novo e inovador programa envolvendo Estados Unidos e Brasil. Mais exatamente, envolvendo a "National Academy of Sciences (NAS)" dos Estados Unidos e o antigo Conselho Nacional de Pesquisas (CNPq), sob a batuta do Prof. Carl Djerrasi do próprio Departamento de Química de Stanford. Ao indagar, no recinto de café (o Gazebo), descobri que se tratava de uma idéia realmente original para abordar o problema vulgarmente chamado de "brain drain" que merece aqui uma abertura para definir os seus objetivos.

\section{OS OBJETIVOS}

A realidade da pesquisa acadêmica no terceiro mundo na década de $60^{1}$ era realmente de desanimar em termos das condições oferecidas para a sua execução e, portanto, a sua qualidade a nível internacional. Como conseqüência, era muito comum qualquer pesquisador de qualidade advindo do terceiro mundo aproveitar o seu estágio de doutorado ou pós-doutorado para permanecer no país do primeiro mundo, ainda mais quando somado aos salários oferecidos.

De certa forma, o primeiro mundo aceitava esta situação com muita complacência, visto todas as vantagens conseguidas. Por um investimento relativamente baixo o país receptor melhorava a sua produção científica acadêmica, enquanto preparava um novo cientista para seu parque industrial.

Como reverter esta situação altamente prejudicial para o desenvolvimento dos países do terceiro mundo? Simples: levar a pesquisa do primeiro mundo e a pós-graduação mais moderna e treinar os futuros pesquisadores no local, sem que saboreassem os eventuais prazeres do primeiro mundo.

Mais precisamente, o Prof. Djerassi propôs um programa para a Química em que professores americanos de alto renome teriam uma interação científica com colegas brasileiros através de um instrumento novo - um jovem pesquisador escolhido de seu próprio laboratório e enviado para o laboratório do parceiro brasileiro, com a incumbência de implantar suas novas linhas de pesquisa e, simultaneamente, dirigir as atividades formais da pós-graduação nos moldes norte-americanos. Este jovem pesquisador receberia uma

*e-mail: brocksom@terra.com.br bolsa da NAS no magnífico valor de US\$ 6.000,00 anuais e seria chamado de "fellow" (logo transformado em "gringo" no Brasil).

\section{O INÍCIO DO PROGRAMA}

Por uma questão de qualidade e praticidade, o programa fixouse inicialmente nas universidades americanas de Stanford e California Institute of Technology (CalTech) e aqui no Brasil na Universidade de São Paulo (USP) e na Universidade Federal do Rio de Janeiro (UFRJ). Os aspectos mais formais das origens e dos acordos do programa são tratados neste número especial pelos coordenadores dos programas na USP e na UFRJ ${ }^{2} \mathrm{e}$, assim, pretendo ir direto para a minha participação e a área de Síntese Orgânica.

Primeiro, porque a Síntese Orgânica como linha nova? A Síntese Orgânica é a disciplina envolvida nas indústrias de petroquímica, polímeros, plásticos, a química orgânica fina, a indústria farmacêutica e agroquímica, entre outras. Por exemplo, há estatísticas que a indústria farmacêutica britânica rende mais divisas que o turismo. Houve então uma previsão ainda não concretizada que a Síntese Orgânica poderia ajudar a incrementar a economia brasileira.

Entretanto, eu descobri que já havia a indicação dos dois primeiros "fellows", Simon Campbell e Robert Ronald (logo apelido de Robolonça pelo Prof. Nicola Petragnani), para colaborar com o Prof. Marcelo de Moura Campos, do Instituto de Química da USP. Por motivos pessoais, o Prof. Marcelo infelizmente acabou se retirando do comando antes de realmente iniciar as atividades e o Prof. Nicola assumiu este pesado encargo.

Enquanto isso, fui fazer um segundo estágio de pós-doutorado no Departamento de Química da University British Columbia, Vancouver, Canadá, sob a supervisão do Prof. James P. Kutney. Aí é que o meu destino começou mudar, já que eu estava esquecendo o Brasil e planejando voltar para Inglaterra, um belo emprego na indústria farmacêutica, a melhor cerveja do mundo e, obviamente, o melhor futebol do planeta. Mas, lá estavam no laboratório Carlos Camisa Fortes e João Pedro de Sousa, professores da Universidade de Brasília, em fase de doutorado. A amizade entre nós cresceu muito; certamente em algum momento eu comentei sobre o programa NAS/ $\mathrm{CNPq}$ e, de imediato, os dois amigos passaram a me convencer a participar indo ao Brasil.

Então, voltei a consultar o Prof. Bill Johnson sobre o andamento do programa e a possibilidade de participar como futuro "fellow". Surpreendentemente, fui contemplado com uma oferta para substituir o insubstituível Simon Campbell, que estava planejando sua volta para a Inglaterra, para a indústria farmacêutica onde alcança- 
ria fama mundial como inventor do Viagra. Quero crer que a oferta do Prof. Bill Johnson foi tão fulminante porque não havia mais ninguém interessado em vir para cá.

Assim, e em combinação com o Simon Campbell e a NAS, acertei minha vinda ao Brasil, para o Instituto de Química da USP e aos cuidados do Prof. Nicola Petragnani, isto em abril/maio de 1972, em plena época da ditadura militar. Certamente, a minha pretensão de tentar uma pesquisa nova e auxiliar nas atividades de pós-graduação foi reforçada com a certeza de que pelo menos eu teria a oportunidade de ensinar a prática de futebol para os nativos.

Chegando aqui, descobrindo a realidade da situação e ainda reconhecendo os esforços monumentais do Simon, Robolonça, e Nicola, era evidente que havia muito trabalho a fazer. Tomei uma decisão discutível de primeiramente tentar aprender a língua portuguesa em qualidade suficiente para contar piadas, em menos de três meses. Simultaneamente, resolvi tentar organizar melhor a infraestrutura do laboratório e adjacências.

Por que comento isto? Porque descobri o primeiro defeito do programa; o "fellow" tinha somente dois anos para chegar ao Brasil, aprender português, organizar o laboratório, achar alunos de pós-graduação, imprimir seu trabalho de pesquisa, obter resultados publicáveis, iniciar a sua programação de volta e, principalmente, procurar um emprego. Uma tarefa impossível de realizar em somente dois anos! Como conseqüência, houve uma possibilidade do "fellow" virar as costas para os objetivos maiores do programa e trabalhar em benefício próprio, visando seu retorno. A posição de seu substituto não era nada melhor porque teria que fazer as mesmas coisas e ainda continuar com as pesquisas em andamento do seu antecessor.

Um segundo problema constatado era o status do "fellow" perante o Instituto e os colegas brasileiros, pois nos considerávamos novos professores iguais a quaisquer outros recém-contratados. Isso, aliado ao desejo do "fellow" de ser totalmente independente como pesquisador, postura respeitada pelo professor norte-americano, mas nem sempre respeitado no local. Por outro lado, devo frisar que, no meu caso, a relação com o Prof. Nicola Petragnani sempre foi ótima em termos científicos e pessoais, bem como com os outros colegas do Instituto de Química da USP.

Certamente o leitor deve estar perguntando sobre o financiamento da pesquisa, tão importante para novas linhas e, também, iniciantes sem competência comprovada. A NAS montou um escritório em Washington, sob o comando do Sr. Wesley Copeland, para amenizar nossos problemas e também resolver a questão da aquisição de produtos químicos e equipamentos de pequeno porte. Os "fellows" enviavam cartas com as listas dos produtos desejados, e após alguns meses de espera, poderíamos retirar esses materiais no consulado americano em São Paulo. Os produtos eram importados pela "via diplomática" (“diplomatic bag"), que era a única forma naquele momento para se receber produtos químicos (especialmente os nossos sendo tóxicos, inflamáveis e fedorentos) e pequenos equipamentos. Evidentemente, este procedimento conhecido no primeiro mundo como jeitinho, causava uma certa inveja aos colegas brasileiros, o que era prontamente resolvido por mais um jeitinho estrangeiro: passamos a solicitar produtos químicos para estes colegas também.

\section{A CONSOLIDAÇÃO DO PROGRAMA}

Com a presença de excelentes alunos de pós-graduação ${ }^{3}$, herdados do Simon e Robalonça, e a chegada de novos alunos de pósgraduação e de iniciação científica, o grupo cresceu significativamente e a colaboração com o Prof. Nicola começou render as primeiras publicações ${ }^{4}$. Com a minha decisão de permanecer por mais dois anos além dos primeiros dois, comecei lecionar na pós-graduação nas áreas clássicas de síntese orgânica e, ainda, participar mais efetivamente das atividades normais da pós-graduação.

Assim, foram criadas as disciplinas de "Química Orgânica Avançada" entre outras, para atender às necessidades dos alunos de procedências diferentes e com eventuais deficiências na formação da graduação. É importante comentar que os alunos apresentavam ótimo desempenho em disciplinas sofisticadas e de conteúdo muito específico, porém dificuldades com conceitos básicos de química orgânica. Esta idéia depois se espalhou para as outras áreas da Química, mostrando sua relevância.

De forma semelhante, os alunos apresentavam os problemas normais da transição dos cursos de graduação para os de pós-graduação, e do preparo para o futuro como docentes ${ }^{5}$. Em função destes problemas insistimos nas provas em língua inglesa, seminários (assistir e ministrar) e exames de qualificação em moldes mais apropriados. Este início em formular o conteúdo do curso de pós-graduação, para formar um profissional mais adequado à docência e não só para atividade de pesquisa, continua até hoje ${ }^{6}$.

Sem dúvida, considero este aspecto o ponto alto do programa quando analiso os alunos formados em nosso laboratório, em conjunto com o Prof. Nicola.

Em 1974, acho eu, a NAS deixou de patrocinar o programa e ficou totalmente a cargo do $\mathrm{CNPq}$. Certamente, isto causou vários problemas de financiamento dos projetos e até dificuldades quanto às bolsas dos "fellows", que passaram a atrasar sistematicamente e por períodos longos.

\section{UMA AVALIAÇÃO}

Após trinta anos do fim do programa, a tendência de todo e qualquer participante é lembrar somente os aspectos positivos, e tentarei ser um pouco mais crítico. Primeiro, é importante lembrar que toda a pesquisa química brasileira tem forte influência estrangeira começando pelos Profs. Reinboldt e Hauptmann no próprio IQ da USP. A Segunda Guerra Mundial - antes, durante e depois trouxe inúmeros químicos de relevância. Houve um tipo de programa no antigo CPPN (hoje NPPN) da UFRJ com predominância de ingleses, um outro programa de americanos para UNICAMP, e importantes contribuições de argentinos e chilenos, para citar alguns exemplos. Fica difícil separar claramente os efeitos de cada invasão, sem distinguir também os brasileiros que foram à luta sem qualquer apoio estrangeiro e se deram muito bem.

Neste momento pode-se lembrar que a posição soberana dos Estados Unidos em ciências se deve em boa parte aos pós-graduandos e pós-doutorandos estrangeiros, que executam as pesquisas, e ao grande número de cientistas oriundos do mundo inteiro que lideram e inclusive recebem premiações especiais de destaque sendo sempre citados com "cientistas americanos, mas nascidos em ....". Este exemplo serve para reforçar a necessidade de receber cientistas estrangeiros de qualidade.

A partir destas colocações, o programa NAS/CNPq pode ser considerado um sucesso pelas inovações, pelas pesquisas novas, pelos alunos formados que depois se destacaram, pelas influências sobre a pós-graduação brasileira e pelas possibilidades concretas de incorporar a química brasileira no cenário mundial. Também se pode destacar o fato que a relação custo-benefício foi muito baixa, e mostra que é importante em avaliações considerar o investimento perante os resultados conseguidos. Por outro lado, a escolha do "fellow" foi de fundamental importância porque a ciência é conduzida por seres humanos, e a compreensão mútua é essencial, não bastando simplesmente a competência técnica, mas a capacidade de convencimento de maneiras diferentes de atuar. 
Alguns aspectos negativos já foram comentados, e pode se acrescentar a isto a existência de paternalismo e complacência com os alunos, e o desejo de não competir demasiadamente com os colegas. De fato, esta colocação deve ser temperada no sentido de que o primeiro mundo freqüientemente exagera nesta competição e isso deixa de ser saudável.

\section{CONCLUSÃO}

Em retrospecto, pode-se considerar que o programa NAS/CNPq auxiliou bastante no desenvolvimento da pesquisa química brasileira, com um investimento muito baixo e resultados muito significativos.

\section{AGRADECIMENTOS}

O que deveria ser uma lista imensa de pessoas que me receberam com muito carinho, e me deram oportunidades de trabalhar sem restrições, mas com muito apoio, este "gringo" só pode citar alguns. Então, começo com os meus anfitriões e depois amigos os Profs. Marcelo de Moura Campos e Nicola Petragnani. Nunca pode ser demais agradecer o empenho do admirável Prof. Paschoal Senise, que nos amparou até em momentos de desespero financeiro durante os constantes atrasos das bolsas do CNPq.
Aos demais colegas do Departamento de Química Orgânica do IQ da USP, e em especial à Profa. Helena Ferraz que sempre animou os ambientes científico e social, e nos deixa agora com um vazio enorme. Evidentemente, devo reconhecer o apoio institucional das agências de fomento FAPESP, CAPES e CNPq.

\section{REFERÊNCIAS E ANOTAÇÕES}

1. Muitos comentários referentes à época são ainda apropriados hoje.

2. Veja os artigos de Paschoal Senise e Aida Espínola neste mesmo número de Química Nova.

3. Decidi não citar nomes de alunos e alguns colegas com receio de esquecer e omitir pessoas com atuação importante, e destacar de forma excessiva outras pessoas até por motivos de amizade.

4. Por exemplo: Brocksom, T. J.; Petragnani, N.; Rodrigues, R.; J. Org. Chem. 1974, 39, 2114: Campbell, S. F.; Constantino, M. G.; Brocksom, T. J.; Petragnani, N.; Synth. Commun. 1975, 5, 353.

5. Neste aspecto, a situação piorou bastante, e devo dizer que os alunos antigamente possuíam mais maturidade e preparo para os estudos de pósgraduação.

6. Brocksom, T. J.; de Andrade, J. B.; Quim. Nova 1997, 20 número especial, 29. 